\title{
Botany
}

\section{Low levels of inbreeding depression and enhanced fitness in cleistogamous progeny in the annual plant Triodanis perfoliata}

\begin{tabular}{|c|c|}
\hline Journal: & Botany \\
\hline Manuscript ID & cjb-2019-0022.R1 \\
\hline Manuscript Type: & Article \\
\hline $\begin{array}{l}\text { Date Submitted by the } \\
\text { Author: }\end{array}$ & 09-Apr-2019 \\
\hline Complete List of Authors: & $\begin{array}{l}\text { Ansaldi, Beth; Fordham University, Biological Sciences } \\
\text { Weber, Jennifer; Southeast Missouri State University, Plant Biology } \\
\text { Goodwillie, Carol; East Carolina University } \\
\text { Franks, Steven; Fordham University, Biological Sciences }\end{array}$ \\
\hline Keyword: & $\begin{array}{l}\text { breeding system, cleistogamy, mixed mating system, reproductive } \\
\text { ecology, Campanulaceae }\end{array}$ \\
\hline $\begin{array}{r}\text { Is the invited manuscript for } \\
\text { consideration in a Special } \\
\text { Issue? : }\end{array}$ & Not applicable (regular submission) \\
\hline
\end{tabular}

\section{SCHOLARONE ${ }^{m}$ Manuscripts}




\section{Low levels of inbreeding depression and enhanced fitness in cleistogamous progeny in the annual plant Triodanis perfoliata}

Beth H Ansaldi ${ }^{1}$, Jennifer J Weber ${ }^{2}$, Carol Goodwillie ${ }^{3}$ and Steven J Franks ${ }^{1,4}$.

${ }^{1}$ Department of Biology, Fordham University, Bronx, NY 10458

${ }^{2}$ Southeast Missouri State University, Cape Girardeau, MO 63701

${ }^{3}$ Department of Biology, East Carolina University, Mail Stop 551, Greenville, North Carolina 27858

${ }^{4}$ Author for correspondence: Steven J. Franks, 441 E. Fordham Road, Bronx, NY 10458, 718 817-3609 (phone), 718-817-3645 (fax)

SHORT RUNNING TITLE: Low inbreeding depression in a cleistogamous plant 


\section{Abstract}

The maintenance of outcrossing in cleistogamous plants that produce both open,

3 facultatively outcrossing chasmogamous $(\mathrm{CH})$ and closed, obligate selfing cleistogamous

4 (CL) flowers is puzzling because CL reproduction is thought to be more reliable and less

5 costly. A possible explanation for the maintenance of $\mathrm{CH}$ flowers is the avoidance of

6 inbreeding depression. However, inbreeding depression for cleistogamous species has

7 rarely been quantified. In this study, we estimate levels of inbreeding depression in plants

8 from three populations of Triodanis perfoliata (L.) Nieuwl., a dimorphic cleistogamous

9 annual, in greenhouse conditions. Estimates of inbreeding depression at multiple life

10 stages in all three populations were low and often not different from zero. Inbreeding

11 depression at specific life stages varied, with two populations showing later acting

12 inbreeding depression, which is also found in other selfing species. In two of the study

13 populations, selfed CL progeny outperformed selfed $\mathrm{CH}$ progeny, indicating a flower

14 type effect. The low levels of inbreeding depression and the superior fitness of CL

15 compared to selfed $\mathrm{CH}$ flowers we observed make the maintenance of $\mathrm{CH}$ flowers in this

16 system surprising, and suggest that other advantages of outcrossing $\mathrm{CH}$ flowers are likely

17 responsible for maintaining mixed mating in this species.

19 Key words: breeding system, Campanulaceae, cleistogamy, inbreeding depression,

20 mixed mating system, plasticity, reproductive ecology 


\section{Introduction}

25 Plant reproductive systems are remarkably diverse, but the major selective

26 pressures affecting the evolution of plant mating strategies can be distilled into a few key

27 ecological and genetic factors. For instance, inbreeding depression influences the relative

28 favorability of selfing versus outcrossing reproduction (Schoen and Lloyd 1984; Lande

29 and Schemske 1985; Goodwillie et al. 2005). Inbreeding depression describes decreased

30 fitness of progeny resulting from reproduction by two closely related parents or through

31 self-fertilization (Ritland 1984; Charlesworth and Charlesworth 1987; Brown et al. 1990).

32 Genetic explanations of inbreeding depression include increased homozygosity of

33 deleterious recessive alleles and decreased prevalence of advantageous heterozygotes

34 (Charlesworth and Charlesworth 1987; Roff 2002).

35 Selfing lineages are theorized to have low inbreeding depression due to purging of

36 deleterious recessive alleles as they are exposed to selection in homozygous genotypes

37 (Crow 1970; Lande and Schemske 1985; Husband and Schemske 1996; Byers and Waller

38 1999). Selfing species often display particularly low levels of inbreeding depression at

39 early life stages, which reflects strong selection against early-acting lethal recessives

40 (Charlesworth et al. 1990; Husband and Schemske 1996). However, inbreeding

41 depression expressed at later life stages is common in selfing populations (Charlesworth

42 and Charlesworth 1987; Hedrick 1994; Husband and Schemske 1996; Wang et al. 1999;

43 Willis 1999). These later-acting alleles are presumed to have a lesser impact on fitness

44 because older plants are expected to contribute less to reproduction than younger plants

45 (Charlesworth 1980; Kirkwood and Rose 1991). 
A number of factors may select for the evolution of selfing. Because selfing genes

47 are passed on through both the ovule and pollen in the maternal plant, selfing genes are

48 expected to experience a 50\% automatic transmission advantage over outcrossing genes

49 (Fisher 1941; Holsinger 1992). Another factor that may select for selfing is indicated by

50 the reproductive assurance hypothesis, which describes the advantage of selfing over

51 outcrossing when pollination conditions or mate density limit outcrossing reproduction

52 (Darwin 1877; Müller 1883; Baker 1955). The reproductive assurance hypothesis

53 predicts that selfing will be favored in species in which individuals frequently colonize

54 new areas; even when fitness of selfed offspring is quite low, producing any offspring is

55 favorable over producing none. Finally, selfing may facilitate local adaptation by limiting

56 the introduction of maladaptive genes through outcrossing (Antonovics 1968; Jain 1976).

57 The opposing evolutionary forces of inbreeding depression and the automatic

58 transmission advantage are at the center of classical mating system theory, which

59 describes mixed mating (reproduction through a mixture of self- and cross-fertilization)

60 as a transitional state between predominant outcrossing and predominant selfing (Lande

61 and Schemske 1985). Prior theoretical work (Lande and Schemske 1985) demonstrated

62 that purging of deleterious alleles results in changes in the level of inbreeding depression,

63 such that decreasing inbreeding depression corresponds with increasing selfing rates. The

64 correlated evolution of selfing rate and inbreeding depression led to the prediction of the

65 evolution of predominant outcrossing when inbreeding depression is high (selfed progeny

66 are less than half as fit as outcrossed progeny), or predominant selfing when inbreeding

67 depression is low (selfed progeny are more than half as fit as outcrossed progeny).

68 In contrast to this earlier view of mixed mating as a temporary, transitional state, 
69 between selfing and outcrossing, current models of mating system evolution suggest that

70 mixed mating may be evolutionarily stable (Goodwillie et al. 2005). Explanations for the

71 potential stability of mixed mating incorporate other ecological factors beyond inbreeding

72 depression, namely pollination conditions (Holsinger et al. 1984; Schoen and Lloyd

73 1984) and resource availability (Oakley et al. 2007). However, the evolution of mixed

74 mating remains enigmatic to evolutionary plant biologists, and our understanding may be

75 limited by gaps in empirical data that adequately quantify inbreeding depression.

76 The current study focuses on inbreeding depression in a dimorphic cleistogamous

77 plant. Species with dimorphic cleistogamy (referred to hereafter simply as cleistogamy)

78 have a mixed mating system, producing both open, hermaphroditic, chasmogamous $(\mathrm{CH})$

79 flowers and closed, obligately selfing, cleistogamous (CL) flowers. Cleistogamy is

80 thought to be an adaptive reproductive strategy that allows for plasticity in reproduction

81 in response to pollinator and resource environments. Seeds from cleistogamous flowers

82 cost, on average, only one third as much as chasmogamous seeds (Culley and Klooster

83 2007), and thus closed flowers are expected to be favored when pollen and resources are

84 scarce. In contrast, open, potentially outcrossing flowers may have an adaptive advantage

85 when resources are abundant because selfed progeny may suffer from high inbreeding 86 depression.

87 Quantitative knowledge of the fitness consequences of cleistogamy will critically

88 inform our understanding of the factors influencing the evolution of cleistogamy. While

89 inbreeding depression has been studied extensively in a variety of systems (Husband and

90 Schemske 1996), it has been measured in relatively few mixed mating, cleistogamous

91 plant species. Furthermore, previous studies of inbreeding depression in cleistogamy have 
92 largely equated $\mathrm{CH}$ flowers with outcrossing, and compared $\mathrm{CH}$ fitness to $\mathrm{CL}$ fitness for

93 the purpose of quantifying inbreeding depression, which ignores the potential for selfing

94 in hermaphroditic CH flowers (for exceptions see (Culley 2000; Oakley and Winn

95 2008)). In addition, comparison between outcrossed $\mathrm{CH}$ and selfed CL fitness does not

96 account for non-genetic flower type effects on offspring fitness, driven by inherent

97 differences in CL and CH flower types (Culley 2000). Flower type effects on progeny

98 fitness can result from spatial and temporal differences in fruit maturation that affect

99 resource allocation to fruits. For instance, position along the stem and timing of flowering

100 often differs in $\mathrm{CH}$ and CL flowers and may influence resource availability for seed

101 maturation (Ernst 1981; Cavers and Steel 1984).

102 A best but rarely used practice to determine the magnitude of inbreeding

103 depression in cleistogamous species is to compare fitness of selfed $\mathrm{CH}$ progeny to that of

104 outcrossed CH progeny (Culley 2000). Further, a comparison of fitness between CL and

105 selfed $\mathrm{CH}$ progeny can be used to quantify the non-genetic effects of floral type (Culley

106 2000). A study that includes both comparisons can provide critical insight into both

107 genetic and non-genetic factors that influence the evolution and maintenance of a

108 cleistogamous mating system. Additionally, because the magnitude of inbreeding

109 depression may vary across populations and throughout the plant life cycle, studies that

110 quantify inbreeding depression at multiple stages and in more than one population are

111 particularly useful.

112 This study quantifies inbreeding depression and fitness effects of different floral

113 types in greenhouse-grown Triodanis perfoliata (L.) Niewl. (Campanulaceae) plants from

114 three source populations. Specifically, we measured the level of inbreeding depression of 
$115 \mathrm{CH}$ flowers at three stages across the entire life cycle of this annual species. We also

116 compared fitness of experimentally selfed $\mathrm{CH}$ flowers with CL flowers, which are

117 obligately selfing, to determine fitness effects associated with flower type. We used this

118 information on inbreeding depression and flower type effects to test the hypothesis that

119 inbreeding depression potentially favors more expensive $\mathrm{CH}$ flowers and helps to

120 maintain the mixed mating system in this species.

121

\section{Materials and methods}

\section{Study species}

124 Triodanis perfoliata is a dimorphic cleistogamous annual, producing CH and CL

125 flowers on the same plant. This herbaceous plant is native to and considered common

126 throughout North America. Cleistogamous (CL) flowers of this species do not develop a

127 corolla and are obligately self-pollinating, whereas chasmogamous $(\mathrm{CH})$ flowers have a

128 5-petalled, bluish-violet corolla and are capable of both selfing and outcrossing (Trent

129 1942). Fruits resulting from the two flower types are also distinct in size and seed

130 production, with smaller CL fruits producing fewer seeds (Trent 1942; Gara and

131 Muenchow 1990). Chasmogamous flowers are protandrous; the male reproductive phase

132 precedes the female reproductive phase, reducing the likelihood of self-fertilization

133 (Goodwillie et al. 2018). However, some autonomous selfing could occur (Goodwillie et

134 al. 2018). This species exhibits secondary pollen presentation, with relocation of pollen

135 from the anthers to pollen-collecting hairs on the outside of the style prior to anthesis

136 (Goodwillie et al. 2018).

137 


\section{Pollination experiment}

139 Maternal plants were grown in a greenhouse from seeds collected from each of

140 three natural populations in summer 2014. Source populations were located in Falkland,

141 NC near Otter Creek (OC), Lynchburg, VA at the Claytor Nature Study Center (CLA),

142 and Bronx, NY at the New York Botanical Garden (NYBG; GPS coordinates in Table 1).

143 Rough estimates of population sizes were thousands of individuals at OC, 75-100 at

144 CLA, and 25-50 at NYBG. Maternal source plants were collected at least $2 \mathrm{~m}$ apart to

145 minimize relatedness. The pollination experimental design followed previous methods

146 (Culley 2000) and resulted in selfed (from both CL and CH flowers) and outcrossed

147 (from $\mathrm{CH}$ flowers) offspring for 15 maternal plants in each population. Outcross

148 pollination entailed removing anthers from two donor plants, using them to scrape pollen

149 off the style of the paternal plant and coating the receptive stigma surface of the maternal

150 plant until visibly saturated with pollen. At least five flowers (range $=5-8$ ) were

151 outcross-pollinated per maternal plant, each with different pairs of donor plants. For

152 selfed $\mathrm{CH}$ flowers, pollen used for hand pollination originated from flowers within the

153 maternal plant. Fruits of selfed chasmogamous $(\mathrm{CH}-\mathrm{S})$, outcrossed chasmogamous $(\mathrm{CH}-$

$154 \mathrm{OX}$ ) and selfed cleistogamous (CL) flowers were collected upon maturation. Seeds were

155 stored at room temperature for three months prior to planting.

156 Seeds from controlled pollinations or CL flowers were pooled by treatment type

157 for each maternal plant. Fifty seeds were assessed for germination for each of the three

158 progeny types (CH-S, CH-OX, CL) in each maternal family ( $n=6,750$ seeds total). Ten

159 seeds per petri dish were placed on damp filter paper ( 5 petri dishes/family). Germination

160 was analyzed as proportion seeds germinated per petri dish. Petri dishes were arranged in 
161 a spatially randomized design on tables within the greenhouse and germinated at $22^{\circ} \mathrm{C}$

162 under a 14-hour light regime. Germination, determined by visual confirmation of

163 cotyledons, was scored daily for 14 days, then every other day until no further

164 germination was seen (a total of 24 days).

165 Several seeds of each type were potted in twelve individual cone-shaped pots

166 (Cone-Tainers ${ }^{\circledR}$, Stuewe and Sons, Inc., Tangent, OR, USA) filled with potting soil

167 (Sunshine Mix \#1, Sungro, Agawam, MA) and fertilized with Osmocote fertilizer (14-14-

168 14). Within maternal lines, $10-12($ mean $=11.5)$ seedlings of each treatment category

169 survived and were assessed for multiplicative fitness, with fitness multiplied across each

170 measured life stage ( $n=1,550$ offspring total). In instances when multiple seedlings

171 emerged in the same pot, they were thinned before exceeding one $\mathrm{cm}$ in height to one

172 plant per pot. Plants were grown in the greenhouse at $\sim 22^{\circ} \mathrm{C}$ under a 14-hour light

173 regime, watered daily and fertilized once weekly until senescence. Plants were arranged

174 haphazardly, and all pots were rotated several times weekly to reduce the possibility of

175 positional effects. Upon senescence, total number of flowers (inclusive of CH and CL

176 types) was counted. Aboveground biomass was harvested, dried to constant weight at $80^{\circ}$

$177 \mathrm{C}$ and weighed to the nearest $\mathrm{mg}$.

179 Detecting inbreeding depression and flower type effects at different stages

180 To understand the effect of progeny type (CH-S, CH-OX, CL) on fitness at each

181 stage, we used mixed models (Crawley 2012) to compare values for proportional

182 germination, biomass, and flower production across progeny types with treatment

183 category as a fixed effect and maternal plant as a random effect for each study 
184 population. All statistical analysis was done separately for each population. Models were

185 built using the lme4 package version 1.1-7 (Bates et al. 2015) in R (R Core Development

186 Team 2013). General linear mixed models were used to determine the effect of treatment

187 (i.e., progeny type) on flower number and biomass (glm function). We built models for

188 proportional seed germination using generalized linear mixed models with a binomial

189 error distribution and a logit link function (glmer function). Model significance was

190 determined using the ANOVA function in the car package, version 2.0-25, in R (Fox and

191 Weisberg 2011). When ANOVA results did not show a significant effect of progeny type

192 on trait values, the results test statistic shown was the Wald $\chi^{2}$. When the ANOVA

193 revealed a significant effect of progeny type on trait values, we used Tukey's post hoc

194 tests to determine significant differences between $\mathrm{CH}-\mathrm{S}$ and $\mathrm{CH}-\mathrm{OX}$ progeny, and

195 between $\mathrm{CH}-\mathrm{S}$ and CL progeny, with the test statistic the $Z$-score (multcomp package,

196 version 1.4-1, glht function; (Hothorn et al. 2008)). A finding of significantly $(P<0.05)$

197 lower performance in $\mathrm{CH}-\mathrm{S}$ than in $\mathrm{CH}-\mathrm{OX}$ progeny indicated inbreeding depression. A

198 significant difference between CH-S and CL progeny indicated a significant flower type

199 effect.

200 We assessed variation in fitness across maternal lines by comparing log-

201 likelihood of models with and without the inclusion of maternal family as a random effect

202 (likelihood ratio test). Models for comparison of glmer and corresponding glm models

203 (lacking maternal effects) were made in glmmADMB Version 0.8.3.3, which can handle

204 both glmer and glm objects (Skaug et al. 2012). The glmmADMB package provides the

205 same estimates as the lme4 package, because both use Laplace approximation, but the

206 glmmADMB allows for likelihood comparison of models lacking random effects, 
207 whereas the lmer package does not (Bolker et al. 2009). Comparison between models was

208 made using the ANOVA function in R. A significant $P$-value, paired with lower log-

209 likelihood of the model including maternal effects, indicated that maternal effects were

210 significant. Because glmmADMB cannot handle linear or linear mixed models, RLRsim

211 version 3.1-3 was used for comparison of the lmer models and corresponding linear

212 model (excluding maternal plant as a random effect; (Scheipl et al. 2008)).

\section{Cumulative inbreeding depression $(\delta)$ and flower type effects}

215 The inbreeding depression coefficient $(\delta)$ is quantified at the population-level as:

216 one minus the relative fitness of selfed to outcrossed progeny $\left(W_{\mathrm{CH}-\mathrm{S}} / W_{\mathrm{CH}-\mathrm{OX}}\right)$ at each

217 life stage (Equation 1). In species with both $\mathrm{CH}$ and CL flowers, the relative fitness of CL

218 flowers compared to selfed $\mathrm{CH}$ flowers quantifies the flower type effect on fitness

219 (Equation 2; Culley 2000). The cumulative inbreeding depression coefficient quantifies

220 relative fitness across the entire life cycle and is calculated by multiplying relative fitness

221 of individual life stages together and subtracting that product from one. Because two of

222 the measured traits, biomass and flower number, are both representative of the adult life

223 stage, we included only flower number (the more direct measure of fitness potential) in

224 the calculation of cumulative relative fitness.

$$
\text { Equation } 1 \quad \delta=1-\left(\frac{W_{C H-S}}{W_{C H-O X}}\right)
$$

While significant inbreeding depression is detected as greater fitness of

$$
\text { Equation } 2 \quad W_{r e l-C L}=1-\frac{W_{C L}}{W_{C H-S}}
$$

outcrossed than selfed progeny for each individual life stage (see section above), the 
230 inbreeding depression coefficient provides information about the magnitude of

231 inbreeding depression. To test whether cumulative population-level inbreeding

232 depression coefficients and flower effect coefficients were significantly different from

233 zero, 95\% confidence intervals (CI) were generated by bootstrapping with resampling in

234 R. Population means were considered significant when the confidence interval did not

235 include zero.

\section{$237 \quad$ Results}

\section{Inbreeding depression at different stages}

239 The magnitude of inbreeding depression varied across life stages, and patterns

240 differed by population, but in general, inbreeding depression coefficients were low and

241 often not significantly different from zero. Differences in $\mathrm{CH}-\mathrm{OX}$ and $\mathrm{CH}-\mathrm{S}$ germination

242 provided evidence for inbreeding depression in the CLA and OC populations $(\delta=0.09, Z$

$243=-4.32, P<0.0001 ;$ and $\delta=0.05, Z=-4.56, P<0.0001$, respectively; Fig 1). In the

244 NYBG population, mean germination was similar for $\mathrm{CH}-\mathrm{OX}$ and $\mathrm{CH}-\mathrm{S}$ plants $(\delta=-$

2450.03 , Wald $\chi^{2}=4.39, P=0.11$; Fig 1), indicating a lack of inbreeding depression for this

246 population at this life stage.

247 In the OC population, inbreeding depression was significant for biomass: $\mathrm{CH}-\mathrm{S}$

248 progeny weighed $16 \%$ less than $\mathrm{CH}-\mathrm{OX}$ progeny $(\delta=0.16, Z=-4.03, P<0.001$; Fig 1).

249 Inbreeding depression was not significant for biomass in the NYBG or CLA populations

$250\left(\delta=0.22, Z=-2.18, P=0.074 ;\right.$ and $\delta=0.06$, Wald $\chi^{2}=4.45, P=0.11$, respectively; Fig

251 1). Inbreeding depression in flower production was found in OC and NYBG populations,

252 with $17 \%$ and $26 \%$ lower flower production in $\mathrm{CH}-\mathrm{S}$ plants, compared to $\mathrm{CH}-\mathrm{OX}$ plants, 
253 respectively $(\delta=0.17, Z=-3.85, P<0.001$; and $\delta=0.26 Z=-2.65, P=0.022$,

254 respectively; Fig 1). Inbreeding depression was not significant at flower production for

255 the CLA population $\left(\delta=0.02\right.$, Wald $\chi^{2}=1.11, P=0.575$, Fig 1). Data for germination,

256 biomass, and flower production for all populations can be found in the supplementary

257 information (Supplementary Table S1).

258 Comparison of log-likelihood of models with and without maternal family as a

259 random effect detected significant variation in fitness across maternal lines for all life

260 stages in all study population (all $P$-values $<0.0001$; Supplementary Table S2). The

261 magnitude of inbreeding depression varied across maternal families and across life stages

262 (Fig 2).

263

264 Cumulative inbreeding depression $(\delta)$

265 We observed no significant population-level lifetime inbreeding depression

266 coefficients in any of the study populations, as indicated by bootstrapped $95 \%$ confidence

267 intervals that overlapped with zero (Table 1, Fig 3). Thus, despite some evidence for low

268 but significant inbreeding depression at some individual life stages for some populations

269 (see above), there was no evidence for cumulative inbreeding depression across the life

270 stages for any of the populations.

271

272 Flower type effects between $\mathrm{CH}$ selfed and CL progeny

273 The effect of flower type on progeny fitness, evaluated by comparison of selfed

$274 \mathrm{CH}$ and CL progeny, varied across life stages and across populations (Fig 1). 
275 The CLA population exhibited no significant flower type effects at any life stage and had

276 a low cumulative flower effect coefficient (Equation 2) that was not significantly

277 different from zero $(-0.12(C I=-0.43-0.20)$; Figs. 1, 3; Table 1). The OC population

278 exhibited flower type effects at germination; seeds produced by $\mathrm{CH}-\mathrm{S}$ flowers had an

279 average germination rate that was $20 \%$ lower than those from CL flowers $(Z=2.95, P=$

$280 \quad 0.009$; Fig. 1). Further, the cumulative flower effect coefficient was significantly

281 different from zero for OC (- $0.43(C I=-0.77--0.08)$; Table 1, Fig. 3). In the NYBG

282 population, $\mathrm{CH}-\mathrm{S}$ progeny produced $23 \%$ fewer flowers than $\mathrm{CL}$ progeny $(Z=-2.6, P=$

283 0.027; Fig 1). The overall flower effect coefficient for NYBG plants was also

284 significantly different from zero $(-0.37(C I=-0.70--0.03)$; Table 1, Fig. 3). Negative

285 cumulative flower effect coefficients in OC and NYBG indicates higher fitness of

286 progeny produced by CL relative to $\mathrm{CH}-\mathrm{S}$ flowers.

288 Discussion

289 Low inbreeding depression

290 Inbreeding depression is thought to be a major reason for the maintenance of

291 more energetically costly outcrossing flowers in species exhibiting dimorphic

292 cleistogamy (Culley and Klooster 2007). However, we did not find substantial levels of

293 inbreeding depression in the mixed cleistogamous species T. perfoliata. Our estimates of

294 cumulative inbreeding depression across the life cycle were not significantly different

295 from zero. While some estimates of inbreeding depression at individual life stages in

296 some populations were significantly different from zero, all were very low, indicating a

297 lack of evidence for strong inbreeding depression. Therefore, it does not appear that 
298 inbreeding depression alone can explain the maintenance of the more showy, facultative 299 outcrossing CH flowers in T. perfiolata.

300 Simple models of mating system evolution predict that predominantly outcrossing

301 should occur when inbreeding depression coefficents are above 0.5 (Lande and Schemske

302 1985), which is well above what we observed. However, pollen discounting, which is the

303 reduction in outcross fitness as a result of selfing (Holsinger and Thomson 1994) could

304 reduce this critical threshold (de Jong and Klinkhamer 2005). Because CL flowers only

305 self, they experience $100 \%$ pollen discounting. Thus production of outcrossing,

306 chasmogamous flowers could potentially be selected for at inbreeding depression values

307 below 0.5 in cleistogamous species, although differences in the costs and seed production

308 of the two flower types are also expected to modify the threshold level (Schoen and

309 Lloyd 1984).

310 Our estimates of inbreeding depression levels and those of the two other studies

311 that quantify inbreeding depression without conflating $\mathrm{CH}$ flowers as outcrossing in

312 cleistogamous species were all below 0.5 (Culley 2000; Oakley and Winn 2008). One

313 study (Culley 2000) reported a lifetime inbreeding depression estimate of 0.10 for

314 greenhouse grown, perennial, Viola canadensis L. plants, and another study (Oakley and

315 Winn 2008) found a lifetime inbreeding depression value of 0.43 in the cleistogamous

316 perennial, Viola septemloba Leconte.

317 The apparent lack of inbreeding depression we found leads to the question of

318 what other factors can account for the maintenance of $\mathrm{CH}$ flowers. Across all

319 cleistogamous species for which the benefits and costs have been quantified, $\mathrm{CH}$

320 reproduction is one-third as reliable and twice as costly as CL reproduction (Oakley et al. 
321 2007). But the extent to which CL flower and fruit production are relatively less costly,

322 as well as the value of CL flowers in providing reproductive assurance will vary with

323 species. In T. perfoliata, $\mathrm{CH}$ reproduction is not pollen limited, and CL fruits produce

324 only $10-50 \%$ the seeds of $\mathrm{CH}$ fruits, depending on pollination conditions, so reproductive

325 assurance via CL flowers may not be as important in this species (Ansaldi et al. 2018).

326 Maintenance of cleistogamous mixed mating also involves the adaptive advantage of

327 plastic responses to environmental heterogeneity via production of the flower type that

328 best suits the environmental conditions (Schoen and Lloyd 1984). High pollination and

329 resource availability are frequently invoked as conditions that favor the production of

$330 \mathrm{CH}$, outcrossed flowers. However, the advantage of outcrossing in these models is the

331 avoidance of inbreeding depression, which does not appear to be an important factor in $T$.

332 perfoliata. One alternative explanation for the maintenance of $\mathrm{CH}$ flowers suggests that

$333 \mathrm{CH}$ flowers may be advantageous as a means to procure new, potentially adaptive alleles,

334 while CL flowers provide a means for uninterrupted selfing, and therefore proliferation of

335 favorable alleles introduced by $\mathrm{CH}$ reproduction ( $\mathrm{Lu} 2002)$. However, empirical evidence

336 explaining the concurrent production of $\mathrm{CH}$ and $\mathrm{CL}$ flowers remains inconclusive.

337 Our results are consistent with historically high selfing rates causing the purging

338 of deleterious recessive alleles in T. perfoliata. Average estimates of inbreeding

339 depression coefficients for predominantly selfing species are 0.23 , which is lower than

340 the estimate of 0.53 for primarily outcrossing species (Crow 1970; Barrett and

341 Charlesworth 1991; Husband and Schemske 1996; Byers and Waller 1999). Overall

342 selfing rates are unknown in T. perfoliata, but are likely to be high due to a high

343 proportional production of CL flowers combined with the capacity for selfing in $\mathrm{CH}$ 
344 flowers; (average \% chasmogamy $\pm 1 \mathrm{SE}=23 \pm 15 \%$ (Ansaldi et al. 2018)). With this

345 reduced genetic load, CL flowers could be maintained because selfing would not result in

346 the loss of fitness, and would produce the low estimates of inbreeding depression that we

347 found in this study.

348 Estimates of inbreeding depression can be influenced by whether the study is

349 conducted in the greenhouse or the field, but the effects of the conditions on estimates of

350 inbreeding depression is controversial. Greenhouse experiments, like the present study,

351 have the advantage of minimizing micro-environmental variation, which is present to a

352 greater extent in the field, and which can cause errors in estimates of inbreeding

353 depression because differences among progeny may be artifacts of relatively favorable or

354 unfavorable micro-environmental conditions (Clay and Antonovics 1985). However,

355 estimates of inbreeding depression from greenhouse experiments could potentially be

356 artificially low due to lack of stress and competition in the greenhouse. Some previous

357 studies found that measures of inbreeding depression in greenhouse conditions were

358 lower than that found in the field (Dudash 1990; Montalvo 1994; Roles and Conner

359 2008). But a meta-analysis failed to detect differences in inbreeding depression estimates

360 between greenhouse compared to field studies (Angeloni et al. 2011). Furthermore,

361 stress, which is generally lower in the greenhouse than in the field, could potentially

362 influence estimates of inbreeding depression, but there is no clear relationship between

363 stress and inbreeding depression (Armbruster and Reed 2005). One experiment on Silene

364 vulgaris (Moench) Garcke found that inbreeding depression was actually lower in

365 stressful conditions (Sandner and Matthies 2016), in contrast to predictions, and other

366 work suggests that severe stress may not lead to greater inbreeding depression for 
367 populations that have generally low inbreeding depression values (Rehling et al. 2019). A

368 study investigating inbreeding depression in the field in this species would be

369 complementary to this work, but would not be free of potential bias nor would it

370 necessarily provide more accurate estimates. It is nevertheless important to recognize that

371 our estimates of inbreeding depression could potentially be underestimates. Furthermore,

372 it is also possible that our estimates of inbreeding depression could have been altered if

373 other fitness components, such as seed production of self versus outcrossed flowers, had

374 been included, but it was unfortunately not feasible to include other components in this

375 study.

376 Because plants in the present study were not emasculated, we cannot eliminate the

377 possibility that some self-pollination occurred in $\mathrm{CH}-\mathrm{OX}$ flowers. $\mathrm{CH}$ flowers in $T$.

378 perfoliata display protrandry, partial separation of the male and female reproductive

379 phase, which inhibits self-pollination (Goodwillie et al. 2018). However, some selfing

380 does occur in $\mathrm{CH}$ flowers of $T$. perfoliata. Experimental floral manipulations showed that

381 some of the selfing is delayed, and may occur as the stigma curls back towards the style

382 in the later stages of anthesis to make contact with self-pollen present on the style

383 (Goodwillie et al. 2018). However, pollination studies in both field and greenhouse

384 indicate that autonomous selfing results in only about $60 \%$ as many seeds as flowers that

385 have been supplemented with self-pollen (Ansaldi et al. 2018; Goodwillie et al. 2018).

386 Therefore, we are reasonably confident that our $\mathrm{CH}-\mathrm{OX}$ progeny were largely the result

387 of our controlled hand-outcross pollinations.

\section{Magnitude of inbreeding depression $(\delta)$ across the life stages}


Variation in the expression of inbreeding depression across life stages is typically

391 the result of different deleterious alleles acting in each life stage. Lethal recessive alleles

392 acting at early life stages should be quickly purged from populations because of their

393 severe negative effect on fitness in the homozygous state (Husband and Schemske 1996).

394 Inbreeding depression in the later life stages is thought to have less of an impact on plant

395 fitness because the relative contribution to reproduction decreases as a plant ages

396 (Charlesworth et al. 1990; Kirkwood and Rose 1991). Therefore, deleterious alleles may

397 accumulate when their effect is mild, resulting in larger inbreeding depression in the later

398 life stages (Charlesworth and Charlesworth 1987; Hedrick 1994; Husband and Schemske

399 1996; Wang et al. 1999; Willis 1999). The pattern observed in the NYBG population is

400 consistent with that of late acting inbreeding depression in predominantly selfing species

401 (Husband and Schemske 1996). Similarly, inbreeding depression in the cleistogamous

402 plant Viola canadensis was low for seed production, flower production and survival, but

403 outcrossed plants produced 14\% more vegetative biomass than selfed plants (Culley

404 2000). And in Viola septemloba, inbreeding depression at the individual life stages was

405 not significant but tended to increase at later life stages (Oakley and Winn 2008). This

406 mechanism of effective purging at early life stages does not explain the patterns observed

407 in CLA or OC plants, where inbreeding depression was expressed either at early life

408 stages or consistently across all life stages, respectively.

\section{$410 \quad$ Variation among maternal lines}

411 Maternal family had a significant impact on plant fitness, and patterns of the

412 magnitude of stage-specific inbreeding varied. In some cases, differences across maternal

413 family were quite pronounced, as is seen in the germination stages of OC and NYBG 
414 populations. In both of these populations, there were two families that exhibited large,

415 negative inbreeding depression coefficients, which indicates that $\mathrm{CH}-\mathrm{S}$ plants were more

416 vigorous than $\mathrm{CH}-\mathrm{OX}$ plants within these lines. Within these maternal families, the

417 negative inbreeding depression coefficients generally resulted from a combination of

418 particularly low $\mathrm{CH}-\mathrm{OX}$ germination (relative to the population mean) and high $\mathrm{CH}-\mathrm{S}$

419 germination. An exception was a maternal family in the OC population where $\mathrm{CH}-\mathrm{OX}$

420 germination was average, but $\mathrm{CH}-\mathrm{S}$ germination was relatively high. The observed low

421 fitness associated with outcrossed progeny is not likely a result of biparental inbreeding,

422 because in a highly selfing population, purging of deleterious alleles is expected to

423 mitigate biparental inbreeding depression (Ritland 1984; Uyenoyama 1986; Brown et al.

424 1990). A more likely explanation is that outcrossing in these families led to unfavorable

425 allelic combinations, resulting in the low germination in outcrossed progeny.

426 The observed variation in inbreeding depression among maternal lines may reflect

427 different genetic loads (i.e. the number of deleterious recessive alleles) present in each

428 family or differences in the scale of the effect of the present alleles (Charlesworth and

429 Charlesworth 1987; Husband and Schemske 1996). It is not unusual to observe

430 differences in inbreeding depression across maternal lines within a population (Dudash et

431 al. 1997; Culley 2000; González-Varo and Traveset 2010). However, maternal variation

432 cannot necessarily be ascribed to inbreeding depression as maternal effects, and other

433 genetic mechanisms can contribute to differences in the relative fitness of outbred and

434 selfed progeny across families (Johnston and Schoen 1994; Fox 2005; Kelly 2005;

435 Moorad and Wade 2005). For instance, outcrossing can introduce novel genetic

436 combinations, while selfed progeny are restricted to inheriting alleles present in the 
437 selfing parent (Fox 2005). And, while selfing should lead to low variance in fitness,

438 outcrossing can lead to higher fitness variance due to the possibility of an unfavorable

439 allelic combination following outcrossing (Waller 1980).

440

441 Flower type effect: CH-S vs CL progeny

$442 \quad \mathrm{CH}$ flowers in dimorphic cleistogamous species such as T. perfoliata can either

443 outcross or self-fertilize. If there is a difference in fitness between offspring produced by

444 selfing $\mathrm{CH}$ flowers and by CL flowers, which are obligately selfing, this would be a

445 flower type effect. Historically, multiple authors have largely assumed that progeny from

$446 \mathrm{CH}$ flowers are the result of outcrossing, thus ignoring potential flower type effects

447 (Wilken 1982; Clay 1983; Waller 1984; Antlfinger 1986; Gara and Muenchow 1990; Lu

448 2002; Winn and Moriuchi 2009). Few prior studies of cleistogamous species

449 experimentally address the potential for non-genetic flower type effects on fitness of

450 progeny (Culley 2000; Oakley and Winn 2008).

451 In this study, we demonstrated differences in fitness between selfed progeny

452 from $\mathrm{CH}$ and $\mathrm{CL}$ flowers in T. perfoliata, showing a flower type effect. In two

453 populations, NYBG and OC, CL progeny were more vigorous than CH-S progeny. Our

454 finding contrasts with another study that failed to find a flower type effect in Viola

455 canadensis (Culley 2000). Our result indicates that CL flowers may have several

456 advantages over $\mathrm{CH}-\mathrm{S}$ flowers, including greater fitness of offspring, being less

457 energetically expensive to produce, and offering reproductive assurance, which can help

458 to explain the maintenance of CL flowers.

$459 \quad$ Flower type effects may arise from inherent differences in CL and $\mathrm{CH}$ fruit 
460 structure, positioning, and timing of maturation. In many species, including T. perfoliata,

461 flowering times for $\mathrm{CL}$ and $\mathrm{CH}$ flowers differ slightly, and it is possible that these

462 differences could lead to differential resource allocation to flower types or other

463 environmental effects during seed maturation. In many species, position along the stem

464 differs between flower types, with primary CL flowers beginning low on the stem and

$465 \mathrm{CH}$ flowers occurring along the upper half of the stem. Positional effects are well

466 documented in the literature, and may result from temporal effects in maturation timing

467 (Ernst 1981; Cavers and Steel 1984) and structural heterogeneity in the maternal plant

468 that influences intra-plant resource allocation (Cheplick 1996; Cheplick and Sung 1998).

469 Differences in $\mathrm{CH}$ and CL flower environment may be even more pronounced in

470 perennial species that produce the flower types in separate seasons and in species with

471 subterranean CL flowers.

472 It is important to note that our estimates of flower type effects are from a

473 greenhouse study, and results could potentially be different in the field. For example, if

474 resource such as nutrients are lower in the field than greenhouse, and nutrient availability

475 influences the relative fitness of CL compared to $\mathrm{CH}$ flowers, flower type effects could

476 differ in magnitude or be absent or even reversed in the field compared to the greenhouse.

477 However, our study populations occur in areas that do not appear to be substantially

478 limiting in nutrients. Furthermore, if nutrients were lower in the field than the

479 greenhouse, we might expect that the relative fitness of CL flowers, which are cheaper to

480 produce, might be even greater rather than less in the field. We expect that our

481 experiments provide reasonable estimates of flower type effects. However, it is possible

482 that field experiments would provide different information on flower type effects. Future 
483 work on flower type effects under different conditions would be useful.

\section{Conclusions}

486 The low levels of inbreeding depression we observed in T. perfoliata suggests the 487 potential for a selective advantage of self-fertilization. Selfing via cleistogamy appears to 488 be particularly advantageous given the flower type effect that we found, with greater 489 fitness from CL than CH-S flowers, as well as the lower cost of CL compared to CH-S 490 flowers. Likely, ongoing high levels of selfing have purged many deleterious recessive 491 alleles in these populations. However, levels of inbreeding depression varied substantially 492 across life stages, indicating that the frequency and effects of deleterious recessive alleles

493 likely varied across life stages. Inbreeding depression also varied widely by maternal 494 family, indicating that individual genetic loads probably vary among genotypes. Further, 495 significant flower effects in these populations indicate that the effects of self-fertilization 496 vary depending on whether it occurs in obligately selfing CL flowers or in facultatively 497 selfing $\mathrm{CH}$ flowers. Specifically, finding that CL progeny are more fit than those from 498 CH-S flowers suggests the need for further study of non-genetic effects that underlie 499 differences in selfed progeny from the two flower types in cleistogamous breeding 500 systems. Overall, low levels of inbreeding depression demonstrate that this factor alone 501 cannot explain the maintenance of $\mathrm{CH}$ flowers, and that other ecological and evolutionary 502 factors should be considered.

503

\section{Acknowledgements}


506 Stockdale and A. Biltz for their assistance in data collection. We are grateful to the Louis

507 Calder Center staff for their support, in particular A. Perrone, P. Del Valle, and M.

508 Lambros. This work was funded by the Louis Calder Center and a grant from the

509 National Science Foundation (DEB-1142784) to S.J. Franks. 


\section{References}

Angeloni, F., Ouborg, N.J., and Leimu, R. 2011. Meta-analysis on the association of population size and life history with inbreeding depression in plants. Biol. Conserv. 144(1): 35-43. doi:https://doi.org/10.1016/j.biocon.2010.08.016.

Ansaldi, B.H., Weber, J.J., and Franks, S.J. 2018. The role of phenotypic plasticity and pollination environment in the cleistogamous, mixed mating breeding system of Triodanis perfoliata. Plant Biol. 20(6): 1068-1074. doi:10.1111/plb.12877.

Antlfinger, A.E. 1986. Field germination and seedling growth of CH and CL progeny of Impatiens capensis (Balsaminaceae). Am. J. Bot. 73(9): 1267-1273. doi:10.2307/2444061.

Antonovics, J. 1968. Evolution in closely adjacent plant populations V. Evolution of self-fertility. Heredity, 23: 219-238. doi:10.1038/hdy.1968.30.

Armbruster, P., and Reed, D.H. 2005. Inbreeding depression in benign and stressful environments. Heredity, 95: 235. doi:10.1038/sj.hdy.6800721.

Baker, H.G. 1955. Self-compatibility and establishment after 'long-distance' dispersal. Evolution, 9(3): 347-349. doi:10.2307/2405656.

Barrett, S.C., and Charlesworth, D. 1991. Effects of a change in the level of inbreeding on the genetic load. Nature, 352(6335): 522-524. doi:10.1038/352522a0.

Bates, D., Mächler, M., Bolker, B., and Walker, S. 2015. Fitting Linear Mixed-Effects Models Using lme4. Journal of Statistical Software 1(1): 1-48.

Bolker, B.M., Brooks, M.E., Clark, C.J., Geange, S.W., Poulsen, J.R., Stevens, M.H.H., and White, J.-S.S. 2009. Generalized linear mixed models: a practical guide for 
ecology and evolution. Trends Ecol. Evol. 24(3): 127-135.

doi:10.1016/j.tree.2008.10.008.

Brown, A., Clegg, M.T., Kahler, A.L., and Weir, B.S. 1990. Genetic characterization of plant mating systems. In Plant population genetics, breeding, and genetic resources Edited by A.H.D. Brown, M.T. Clegg, A.L. Kahler and B.S. Weir. Sinauer Associates Inc., Sunderland, Massachusetts. pp. 145-162.

Byers, D.L., and Waller, D.M. 1999. Do plant populations purge their genetic load? Effects of population size and mating history on inbreeding depression. Annu. Rev. Ecol. Syst. 30(1): 479-513. doi:10.1146/annurev.ecolsys.30.1.479.

Cavers, P.B., and Steel, M.G. 1984. Patterns of change in seed weight over time on individual plants. Am. Nat. 124(3): 324-335.

Charlesworth, B. 1980. The cost of sex in relation to mating system. J. Theor. Biol. 84(4): 655-671. doi:10.1016/S0022-5193(80)80026-9.

Charlesworth, D., and Charlesworth, B. 1987. Inbreeding depression and its evolutionary consequences. Annu. Rev. Ecol. Syst. 18(1): 237-268. doi:10.1146/annurev.es.18.110187.001321.

Charlesworth, D., Morgan, M.T., and Charlesworth, B. 1990. Inbreeding depression, genetic load, and the evolution of outcrossing rates in a multilocus system with no linkage. Evolution, 44(6): 1469-1489. doi:10.1111/j.15585646.1990.tb03839.x.

Cheplick, G.P. 1996. Cleistogamy and seed heteromorphism in Triplasis purpurea (Poaceae). Bull. Torrey Bot. Club 123(1): 25-33. doi:10.2307/2996303. 
Cheplick, G.P., and Sung, L.Y. 1998. Effects of maternal nutrient environment and maturation position on seed heteromorphism, germination, and seedling growth in Triplasis purpurea (Poaceae). Int. J. Plant Sci. 159(2): 338-350.

Clay, K. 1983. The differential establishment of seedlings from chasmogamous and cleistogamous flowers in natural populations of the grass Danthonia spicata (L.) Beauv. Oecologia, 57(1-2): 183-188. doi:10.1007/bf00379579.

Clay, K., and Antonovics, J. 1985. Quantitative variation of progeny from chasmogamous and cleistogamous flowers in the grass Danthonia spicata. Evolution, 39(2): 335-348. doi:10.1111/j.1558-5646.1985.tb05671.x.

Crawley, M.J. 2012. The R Book. John Wiley \& Sons, New York.

Crow, J.F. 1970. Genetic loads and the cost of natural selection. In Mathematical Topics in Population Genetics. Edited by K.I. Kojima. Springer, Berlin. pp. 128177.

Culley, T.M. 2000. Inbreeding depression and floral type fitness differences in Viola canadensis (Violaceae), a species with chasmogamous and cleistogamous flowers. Can. J. Bot. 78(11): 1420-1429. doi:10.1139/b00-115.

Culley, T.M., and Klooster, M.R. 2007. The cleistogamous breeding system: A review of Its frequency, evolution, and ecology in angiosperms. Bot. Rev. 73(1): 1-30.

Darwin, C. 1877. The different forms of flowers on plants of the same species. Charles Murray, London.

de Jong, T., and Klinkhamer, P.G.L. 2005. Evolutionary ecology of plant reproductive strategies. Cambridge University Press, Cambridge, UK. 
Dudash, M.R. 1990. Relative fitness of selfed and outcrossed progeny in a selfcompatible, protandrous species, Sabatia angularis l. (Gentianaceae): A comparison in three environments. Evolution, 44(5): 1129-1139. doi:10.1111/j.1558-5646.1990.tb05220.x.

Dudash, M.R., Carr, D.E., and Fenster, C.B. 1997. Five generations of enforced selfing and outcrossing in Mimulus guttatus: Inbreeding depression variation at the population and family level. Evolution, 51(1): 54-65. doi:10.1111/j.15585646.1997.tb02388.x.

Ernst, W.H.O. 1981. Ecological implication of fruit variability in Phleum arenarium L., an annual dune grass. Flora, 171(4): 387-398. doi:10.1016/S0367$2530(17) 31287-2$.

Fisher, R.A. 1941. Average excess and average effect of a gene substitution. Annals of Eugenics, 11(1): 53-63. doi:10.1111/j.1469-1809.1941.tb02272.x.

Fox, C.W. 2005. Problems in measuring among-family variation in inbreeding depression. Am. J. Bot. 92(11): 1929-1932.

Fox, J., and Weisberg, S. 2011. An $\{$ R $\}$ Companion to Applied Regression. Second ed. Sage, Thousand Oaks, CA.

Gara, B., and Muenchow, G. 1990. Chasmogamy/cleistogamy in Triodanis perfoliata (Campanulaceae): Some CH/CL comparisons in fitness parameters. Am. J. Bot. 77(1): 1-6. doi:10.2307/2444786.

González-Varo, J.P., and Traveset, A. 2010. Among-individual variation in pollen limitation and inbreeding depression in a mixed-mating shrub. Ann. Bot. 106(6): 999-1008. doi:10.1093/aob/mcq200. 
Goodwillie, C., Kalisz, S., and Eckert, C.G. 2005. The evolutionary enigma of mixed mating systems in plants: occurrence, theoretical explanations, and empirical evidence. Annu. Rev. Ecol. Evol. Syst. 36(1): 47-79. doi:10.1146/annurev.ecolsys.36.091704.175539.

Goodwillie, C., Patel, H.R., and Dvorak, D.M. 2018. Does stigma curvature promote delayed selfing? An experimental investigation in Triodanis perfoliata (Campanulaceae). Plant Biol. 20(2): 199-204. doi:10.1111/plb.12677.

Hedrick, P.W. 1994. Purging inbreeding depression and the probability of extinction: full-sib mating. Heredity, 73: 363. doi:10.1038/hdy.1994.183.

Holsinger, K.E. 1992. Functional aspects of mating system evolution in plants. Int. J. Plant Sci. 153(3): iii-v.

Holsinger, K.E., and Thomson, J.D. 1994. Pollen discounting in Erythronium grandiflorum: Mass-action estimates from pollen transfer dynamics. Am. Nat. 144(5): 799-812.

Holsinger, K.E., Feldman, M.W., and Christiansen, F.B. 1984. The evolution of selffertilization in plants: A population genetic model. Am. Nat. 124(3): 446-453.

Hothorn, T., Bretz, F., and Westfall, P. 2008. Simultaneous inference in general parametric models. Biom. J. 50(3): 346-363. doi:10.1002/bimj.200810425.

Husband, B.C., and Schemske, D.W. 1996. Evolution of the magnitude and timing of inbreeding depression in plants. Evolution, 50(1): 54-70. doi:10.1111/j.1558-5646.1996.tb04472.x.

Jain, S.K. 1976. The evolution of inbreeding in plants. Annu. Rev. Ecol. Syst. 7: 469495. 
Johnston, M.O., and Schoen, D.J. 1994. On the measurement of inbreeding depression. Evolution, 48(5): 1735-1741. doi:10.2307/2410261.

Kelly, J.K. 2005. Family level inbreeding depression and the evolution of plant mating systems. New Phytologist, 165(1): 55-62. doi:10.1111/j.14698137.2004.01184.x.

Kirkwood, T.B., and Rose, M.R. 1991. Evolution of senescence: late survival sacrificed for reproduction. Philos. Trans. R. Soc. Lond. B. Biol. Sci. 332(1262): 15-24. doi:10.1098/rstb.1991.0028.

Lande, R., and Schemske, D.W. 1985. The evolution of self-fertilization and inbreeding depression in plants. I. Genetic models. Evolution, 39(1): 24-40. doi:10.1111/j.1558-5646.1985.tb04077.x.

Lu, Y. 2002. Why is cleistogamy a selected reproductive strategy in Impatiens capensis (Balsaminaceae)? Biol. J. Linn. Soc. 75(4): 543-553. doi:doi:10.1046/j.1095-8312.2002.00039.x.

Montalvo, A.M. 1994. Inbreeding depression and maternal effects in Aquilegia caerulea, a partially selfing plant. Ecology, 75(8): 2395-2409. doi:10.2307/1940893.

Moorad, J.A., and Wade, M.J. 2005. A genetic interpretation of the variation in inbreeding depression. Genetics, 170(3): 1373-1384. doi:10.1534/genetics.104.033373.

Müller, H. 1883. The fertilisation of flowers. Macmillan, London. 
Oakley, C.G., and Winn, A.A. 2008. Population-level and family-level inbreeding depression in a cleistogamous perennial. Int. J. Plant Sci. 169(4): 523-530. doi:10.1086/528752.

Oakley, C.G., Moriuchi, K.S., and Winn, A.A. 2007. The maintenance of outcrossing in predominantly selfing species: Ideas and evidence from cleistogamous species. Annu. Rev. Ecol. Evol. Syst. 38(1): 437-457. doi:10.1146/annurev.ecolsys.38.091206.095654.

Rehling, F., Matthies, D., and Sandner, T.M. 2019. Responses of a legume to inbreeding and the intensity of novel and familiar stresses. Ecol. Evol. 9(3): 1255-1267. doi:10.1002/ece3.4831.

Ritland, K. 1984. The effective proportion of self-fertilization with consanguineous matings in inbred populations. Genetics 106(1): 139-152.

Roff, D.A. 2002. Inbreeding depression: tests of the overdominance and partial dominance hypotheses. Evolution, 56(4): 768-775.

Roles, A.J., and Conner, J.K. 2008. Fitness effects of mutation accumulation in a natural outbred population of wild radish (Raphanus raphanistrum): Comparison of field and greenhouse environments. Evolution, 62(5): 10661075. doi:10.1111/j.1558-5646.2008.00354.x.

Sandner, T.M., and Matthies, D. 2016. The effects of stress intensity and stress type on inbreeding depression in Silene vulgaris. Evolution, 70(6): 1225-1238. doi:10.1111/evo.12929.

Scheipl, F., Greven, S., and Küchenhoff, H. 2008. Size and power of tests for a zero random effect variance or polynomial regression in additive and linear mixed 
models. Computational Statistics \& Data Analysis, 52(7): 3283-3299. doi:10.1016/j.csda.2007.10.022.

Schoen, D.J., and Lloyd, D.G. 1984. The selection of cleistogamy and heteromorphic diaspores. Biol. J. Linn. Soc. 23(4): 303-322. doi:10.1111/j.10958312.1984.tb00147.x.

Skaug, H., Fournier, D., Nielsen, A., Magnusson, A., and Bolker, B. 2012. Generalized linear mixed models using AD model builder in R package version 0.7, 2. p. R Package. https://rdrr.io/rforge/glmmADMB/

Trent, J.A. 1942. Studies pertaining to the life history of Specularia perfoliata (L.).A.DC., with special reference to cleistogamy. Transactions of the Kansas Academy of Science (1903-) 45: 152-164. doi:10.2307/3624994.

Uyenoyama, M.K. 1986. Inbreeding and the cost of meiosis: The evolution of selfing in populations practicing biparental inbreeding. Evolution, 40(2): 388-404. doi:10.1111/j.1558-5646.1986.tb00479.x.

Waller, D.M. 1980. Environmental determinants of outcrossing in Impatiens capensis (Balsaminaceae). Evolution, 34(4): 747-761. doi:10.1111/j.15585646.1980.tb04014.x.

Waller, D.M. 1984. Differences in fitness between seedlings derived from cleistogamous and chasmogamous flowers in Impatiens capensis. Evolution, 38(2): 427-440. doi:10.2307/2408501.

Wang, J., Hill, W.G., Charlesworth, D., and Charlesworth, B. 1999. Dynamics of inbreeding depression due to deleterious mutations in small populations: 
mutation parameters and inbreeding rate. Genetics Research, 74(2): 165178.

Wilken, D.H. 1982. The balance between chasmogamy and cleistogamy in Collomia grandiflora (Polemoniaceae). Am. J. Bot. 69(8): 1326-1333. doi:10.2307/2442758.

Willis, J.H. 1999. The role of genes of large effect on inbreeding depression in Mimulus guttatus. Evolution, 53(6): 1678-1691. doi:10.1111/j.15585646.1999.tb04553.x.

Winn, A.A., and Moriuchi, K.S. 2009. The maintenance of mixed mating by cleistogamy in the perennial violet Viola septemloba (Violaceae). Am. J. Bot. 96(11): 2074-2079. doi:10.3732/ajb.0900048. 
Table 1. Population locations, and population-level inbreeding depression (IBD) coefficient $(\delta)$ and flower effect (1-cumulative relative fitness) averaged across maternal lines ( $N=12$ for each population). Bootstrapped $95 \%$ confidence intervals are indicated in parentheses. Subscripts denote statistical significance levels as determined by $95 \%$ confidence intervals that do not overlap with zero. Negative flower effects indicate that CL progeny outperformed CH-S progeny.

\begin{tabular}{llcc}
\hline Population & \multicolumn{1}{c}{ GPS } & Cumulative & Cumulative \\
& Coordinates & IBD mean & flower effect mean \\
\hline OC & $35.43141 \mathrm{~N},-$ & $0.233(-0.142-$ & $-0.426(-0.773--$ \\
& $77.34327 \mathrm{~W}$ & $0.609)$ & $0.0795)^{*}$ \\
NYBG & $40.85984 \mathrm{~N},-$ & $0.226(-0.0335-$ & $-0.365(-0.696--$ \\
& $73.87558 \mathrm{~W}$ & $0.485)$ & $0.0336)^{*}$ \\
& & & \\
CLA & $37.38731 \mathrm{~N},-$ & $0.0972(-0.083-$ & $-0.115(-0.433-0.203)$ \\
& $79.53914 \mathrm{~W}$ & $0.277)$ & \\
\hline${ }^{*} P<0.05,{ }^{* *} P<0.01$ & &
\end{tabular}


Figure 1. Population trait means for germination, flower number, and biomass for each progeny type: $\mathrm{CH}-\mathrm{OX}$ (progeny from outcrossed, chasmogamous flowers), $\mathrm{CH}-\mathrm{S}$ (progeny from selfed, chasmogamous flowers), and CL (progeny from cleistogamous flowers). Bars represent mean ( $\pm 1 \mathrm{SE})$. Bars with different letters were judged to be significantly different at $P<0.05$ as determined by means of Tukey's post-hoc comparison of trait values between offspring types following GLMMs. Marginally significant differences are not annotated here.

Figure 2. Average inbreeding depression coefficient $\left(1-\left(\mathrm{W}_{\mathrm{CH}-\mathrm{S}} / \mathrm{W}_{\mathrm{CH}-\mathrm{OX}}\right)\right)$ by trait for maternal line $(N=15)$ within each of three study populations. Points represent average relative fitness within a maternal plant, with lines connecting life stages within a maternal line.

Figure 3. Cumulative coefficients of inbreeding depression $\left(\left(1-\left(\mathrm{W}_{\mathrm{CH}-\mathrm{S}} / \mathrm{W}_{\mathrm{CH}-\mathrm{OX}}\right)\right)\right.$ and flower effects $\left(\left(1-\left(\mathrm{W}_{\mathrm{CL}} / \mathrm{W}_{\mathrm{CH}-\mathrm{S}}\right)\right)\right.$, averaged across maternal lines within each study population. Asterisks $(*)$ indicate values that are significantly different than zero, as determined by bootstrapped $95 \%$ confidence intervals that do no overlap with zero. The dashed red line indicates a critical threshold inbreeding depression coefficient $(\delta=0.5)$ below which, the Lande and Schemske (1985) mating system model predicts evolution of predominant selfing. 


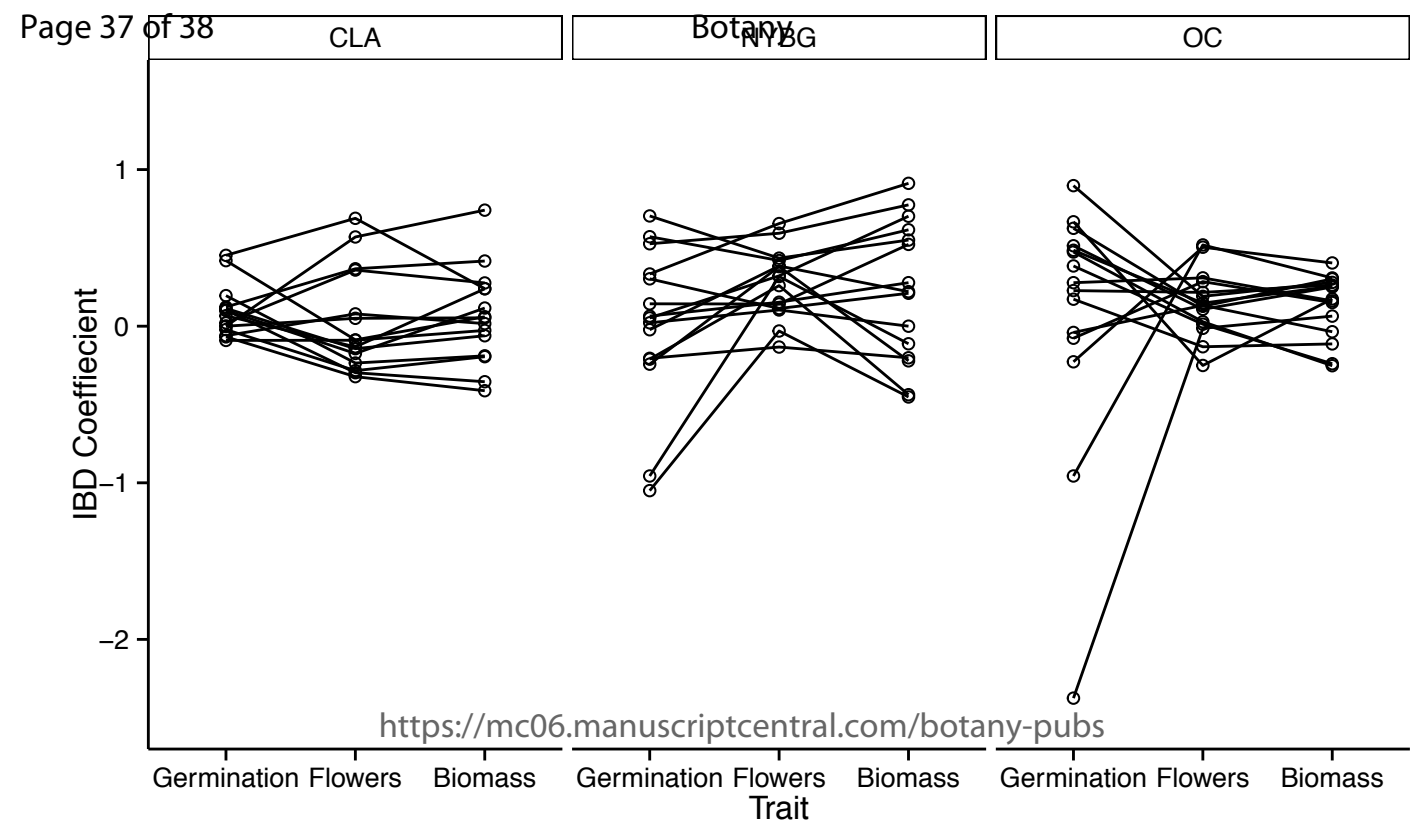




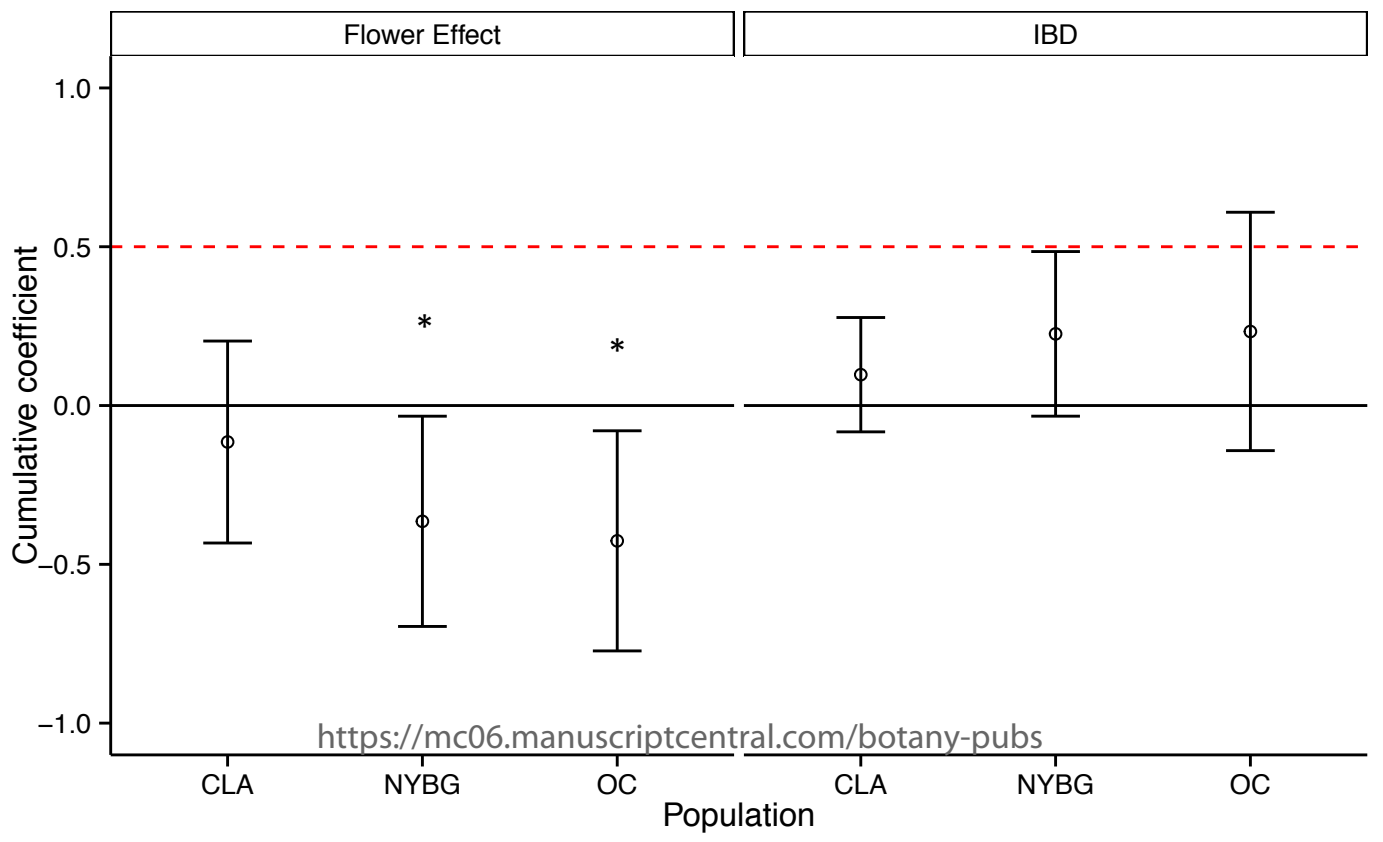

